\title{
Video Display Terminals and Neck Pain: When Ophthalmology Explains the Failure of Biomechanical Intervention
}

\author{
Elvio Ferreira Jr. ${ }^{1,2}$, Karina dos Santos Rocha Ferreira ${ }^{2}$, \\ and Graziela dos Santos Rocha Ferreira ${ }^{2,3}$ \\ ${ }^{1}$ Occupational Safety \& Health Service, São Camilo College, Av. Nazaré 1501, \\ São Paulo, SP 04263-200, Brazil \\ ${ }^{2}$ The Geraldo Ferreira Institute of Medicine, R. Vergueiro 3185 cj.44, \\ São Paulo, SP 04101-300, Brazil \\ ${ }^{3}$ Medical College, University of São Paulo, Av. Dr. Arnaldo 455, \\ São Paulo, SP 01246-903, Brazil \\ elvio@scamilo.edu.br
}

\begin{abstract}
This case report presents a video display terminal (VDT) user complaining of neck pain. It was suggested that her complains would be due to the low position of her computer display. However, raising the monitor actually worsened the discomfort. Being presbyopic and wearing varifocal lenses, she actually was undercorrected — wearing new lenses (with higher reading addition) improved her symptoms. The role of refraction errors as a cause of neck pain and the importance of eye examinations for VDT users are discussed.
\end{abstract}

Keywords: neck pain, video display terminals, refractive errors, ergonomics.

\section{Background}

The neck, back, and brachial plexus seem to be a primary site of musculoskeletal discomfort among video display terminal (VDT) users. [1] Pain symptoms in the neck and shoulder may coexist, overlap and quite frequently no tissue damage can be revealed. [2] Several studies have documented a relation between trapezius load (in particular, static load) and development of musculoskeletal discomfort in the upper part of the body. [3] As with most chronic diseases, musculoskeletal disorders have multiple risk factors. [4] A relation between visual discomfort and pain in the neck has been described. [5] Uncorrected refractive errors lead to postural changes of the head and the cervical spine that, in turn, put more stress on the neck muscles and elicit myofascial pain. [6]

Work posture and postural load of the neck and shoulder muscles during VDT work when correcting presbyopia with different types of multifocal lenses where studied by many authors [7, 8] Single-vision lenses lead to a larger head flexion angle, which is usually considered to be an advantage compared with extension of the neck often observed when wearing multifocals. [9] 
This case report illustrates how correct spectacles prescription is important to avoid neck pain in VDT users.

\section{Case Report}

ID: AML, female, 51, administrative officer.

In June, 2005, she requested the Occupational Safety and Health Service (OSHS) a support for her computer's VDT. She claimed she had pain in the backside of her neck and was under physical therapy. She said her physical therapist had suggested that her pain would be due to the position of her computer display — which would be way too low.

The safety technician inspected the workplace and confirmed the hypothesis of the low position of the display. He installed a monitor raiser, compatible with the user's anthropometry - the top of the display aligned with her eyes aiming the horizon. Although optimal monitor height placement is still under debate, [10] in our service we recommend that for VDT work, the center of the monitor should be located within a viewing angle of $0^{\circ}$ to $-17,5^{\circ}$ as described by Sommerich et al. [11].

One week later, the safety technician paid her another visit to check if the problem was solved. However, he was astonished to find out that she had spontaneously taken the monitor stand off, and had put the display back to its original low position. Eventually, she claimed the support made her work "extremely uncomfortable." At that moment, she was referred to the Occupational Physician.

At the doctor's office, she claimed feeling recurrent neck pain for about three months. She had already seen an Orthopedist who diagnosed myalgia, prescribed nonsteroidal anti-inflammatory drugs and physical therapy. She also had hypothyroidism (controlled under thyroxine $75 \mu \mathrm{g} /$ day) and wore varifocal glasses.

When asked about her last visit to the Ophthalmologist (which had been three months before), she said he had prescribed new glasses - but she was still wearing the old ones (prescribed two years before) because the new lenses were "too expensive."

Her physical examination showed no more than tender trapezium muscles.

The hypothesis that she had undercorrected presbyopia - which would explain all her complains — was made.

She was then asked to bring her new glasses prescription to confirm the hypothesis.

Her old glasses' prescription was:

$$
\begin{aligned}
& \text { OD: }-3,00 \diamond-1,25 \times 180^{\circ} \mathrm{ad}+1,50 \\
& \text { OS: }-2,75 \diamond-0,75 \times 180^{\circ} \mathrm{ad}+1,50
\end{aligned}
$$

i.e., she had mild compound myopia with presbyopia.

And her new prescription was:

$$
\begin{aligned}
& \text { OD: }-2,75 \diamond-1,00 \times 180^{\circ} \mathrm{ad}+2,00 \\
& \text { OS: }-2,75 \diamond-0,75 \times 180^{\circ} \mathrm{ad}+2,00
\end{aligned}
$$

which revealed a progression of her accommodation deficit.

Hypothesis confirmed, she was oriented to wear new glasses, after what she became comfortable with her VDT and, moreover, without pain. 


\section{Discussion}

To fully understand what happened in this case, it is necessary to understand both the natural history of presbyopia and how varifocal (or progressive) lenses work.

Presbyopia is the progressive failure of the eye lens to focus nearby objects due to aging. It usually shows up in the mid-40's. As the individual gets older, the eye lens becomes harder and progressively loses its capacity to alter its antero-posterior diameter (i.e., its capacity to higher its power and focus nearby objects decreases, resulting in the condition where the field of focus is very limited). [12] As years go by, the presbyopic individual needs more and more positive powered lenses to see nearby objects clearly.

In order to correct presbyopia, convex (for near vision), bifocal (for near and distance vision) or varifocal (for close, mid-range and long-distance vision) lenses are prescribed. Convex are single vision lenses. Bifocals and varifocals are lenses which have different powers in their upper and lower halves (Fig. 1). The lower halves contain an reading addition, which is

$$
x=(1 / y)-(z / 2)
$$

where $x$ stands for the reading addition (in diopters), $y$ stands for the reading distance (in meters) and $z$ stands for the amplitude of accomodation (in diopters). [13]
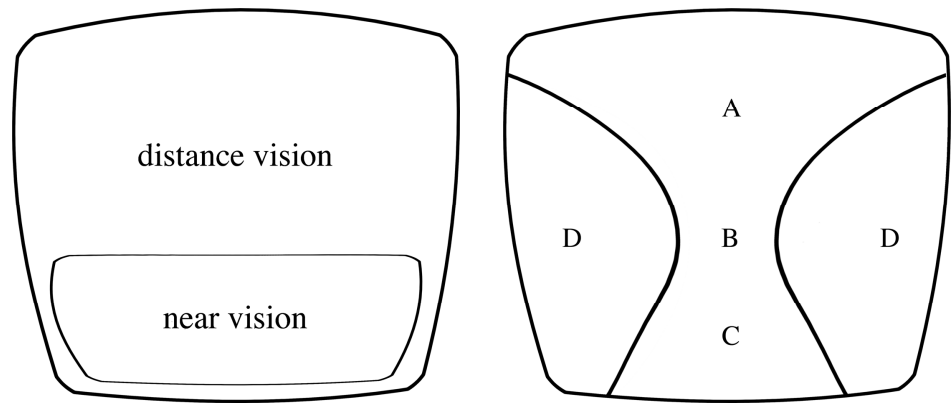

Fig. 1. Bifocal (on the left) and varifocal (on the right) lenses. Note the areas designed for longdistance (A), mid-range (B) and near (C) vision in the varifocal lens and its unwanted peripheral astigmatism (D).

Unlike bifocals, varifocal lenses have no visible dividing lines between the different corrections. Instead, they have a graduated section in which the power of the lens progresses smoothly from one prescription to the other, allowing the wearer to see clearly at all distances. They are not only intended to give the subject a clear vision of nearby and far objects (what is easily obtained which bifocal lenses), but also of objects situated at intermediate distances. However, in order to achieve that effect, any lens with multifocal optics comes with unwanted peripheral astigmatism. [14] 
In correcting the vision of VDT users, it is of primary importance to remember that the viewing distance for VDT images is usually greater - in the neighborhood of 48 to $65 \mathrm{~cm}$ - than the distance for reading hard copy. [15]

Two years before, when the first glasses were prescribed, the old glasses' lenses provided clear vision for far, intermediate-distance and near objects. As the years went by, the patient became more presbyopic — or, in other words, her glasses could provide her clear vision of far and mean-distance objects only. And, to achieve that (focus intermediate-distance objects, such as the VDT), she had to look through the lower third of the lenses. Doing that, she had to tilt her head back extending her neck.

When the support was added, she had to extend her neck even more - worsening the pain.

Possible solutions for the uncomfortable head position adopted by those wearing bifocals or varifocals to view the screen through the appropriate portion of the lens include lowering the screen or prescribing a separate pair of single vision spectacles adjusted for the VDT viewing distance. [16]

In this case, just wearing new multifocal lenses with an adequate reading addition provided the worker comfort.

\section{Summary}

This case enforces both the importance of the Occupational Physician evaluation as well as the necessity of assuming a holistic approach of the individual and his workplace, taking account of workstation design, workpractices and psychological factors as well as optometric data when establishing an ergonomic intervention.

As recommended by the World Health Organization [17] all VDT operators beyond age 40 years should have eye examinations — including both refraction and visual acuity — by examiners trained in visual ergonomics, especially for persons who report musculoskeletal or eyestrain symptoms.

\section{References}

1. Lim, S.-Y., Sauter, S.L., Schnorr, T.M.: Occupational Health Aspects of Work with Video Display Terminals. In: Rom, W.N. (ed.) Environmental and Occupational Medicine, 3rd edn., pp. 1333-1344. Lippincott-Raven Publishers, Philadelphia (1998)

2. Ming, Z., Närhi, M., Siivola, J.: Neck and shoulder pain related to computer use. Pathophysiology 11, 51-56 (2004)

3. Horgen, G., Aarås, A., Thoresen, M.: Will Visual Discomfort among Visual Display Unit (VDU) Users Change in Development When Moving from Single Vision Lenses to Specially Designed VDU Progressive Lenses? Optometry and Vision Science 81, 341-349 (2004)

4. Punnett, L., Wegman, D.H.: Work related musculoskeletal disorders: the epidemiologic evidence and the debate. Journal of Electromyography and Kinesiology 14, 13-23 (2004)

5. Aarås, A., Horgen, G., Bjørset, H.-H., Ro, O., Thoresen, M.: Musculoskeletal, visual and psicosocial stress in VDU operators before and after multidisciplinary ergonomic interventions. Applied Ergonomics 29, 335-354 (1998) 
6. Melis, M.: Headache Associated With Refractive Errors: Overestimated or Overlooked? Headache 43, 297-298 (2003)

7. Horgen, G., Aarås, A., Fagerthun, H., Larsen, S.: Is there a reduction in postural load when wearing progressive lenses during VDT work over a three-month period? Applied Ergonomics 26, 165-171 (1995)

8. Horgen, G., Aarås, A., Fagerthun, H., Larsen, S.: The work posture and postural load of the neck/shoulder muscles when correcting presbyopia with different types of multifocal lenses on VDU-workers. In: Smith, M.J., Salvendy, G. (eds.) Work With Computers: Organizational, Management, Stress and Health Aspects, pp. 338-347. Elsevier Science Publishers, Amsterdam (1989)

9. Harms-Ringdahl, K.: An assessment of shoulder exercise and load elicited pain in cervical spine. Scandinavian Journal of Rehabilitation Medicine Supplement, vol. 14 (1986)

10. Babski-Reeves, K., Stanfield, J., Hughes, L.: Assessment of video display workstation set up on risk factors associated with the development of low back and neck discomfort. International Journal of Industrial Ergonomics 35, 593-604 (2005)

11. Sommerich, C., Joines, S., Psihogios, J.: Effects of VDT viewing angle on user biomechanics, comfort, and preference. In: Human Factors and Ergonomics Society 42nd Annual Meeting. Chicago, pp. 861-865 (1998)

12. Kalsi, M., Heron, G., Charman, N.: Changes in the static accommodation response with age. Ophthalmic and Physiological Optics 21, 77-84 (2001)

13. Sant'Anna, N.A., Uras, R.: Lentes de Correção de Presbiopia. In: Bicas, H.E.A., Alves, A.A., Uras, R. (eds.): Refratometria Ocular. Cultura Médica, Rio de Janeiro, pp. 259-267 (2005)

14. Sheedy, J.E., Hardy, R.F.: The optics of occupational progressive lenses. Optometry 76, 432-441 (2005)

15. Piccoli, B., Braga, M., Zambelli, P.L., Bergamasch, A.: Viewing distance variation and related ophthalmological changes in office activities with and without VDUs. Ergonomics 39, 719-728 (1996)

16. Thomson, W.D.: Eye problems and visual display terminals - the facts and the fallacies. Ophthalmic and Physiological Optics 18, 111-119 (1998)

17. World Health Organization.: Update on Visual Display Terminals and Workers' Health. World Health Organization, Geneva (1990) 